University for Business and Technology in Kosovo

UBT Knowledge Center

UBT International Conference

2017 UBT International Conference

Oct 29th, 11:00 AM - 1:00 PM

\title{
Negative Impacts (SBS) in residential buildings case studies from Kosovo
}

\author{
Muhamet Ahmeti \\ University for Business and Technology, muhamet.ahmeti@ubt-uni.net \\ Mimoza Sylejmani \\ University for Business and Technology
}

Follow this and additional works at: https://knowledgecenter.ubt-uni.net/conference

Part of the Civil Engineering Commons

\section{Recommended Citation}

Ahmeti, Muhamet and Sylejmani, Mimoza, "Negative Impacts (SBS) in residential buildings case studies from Kosovo" (2017). UBT International Conference. 52.

https://knowledgecenter.ubt-uni.net/conference/2017/all-events/52

This Event is brought to you for free and open access by the Publication and Journals at UBT Knowledge Center. It has been accepted for inclusion in UBT International Conference by an authorized administrator of UBT Knowledge Center. For more information, please contact knowledge.center@ubt-uni.net. 


\title{
Negative Impacts (SBS) in residential buildings case studies from Kosovo
}

\author{
Muhamet Ahmeti ${ }^{1}$, Mimoza Sylejmani ${ }^{1}$ \\ UBT - Higher Education Institution, Prishtinë, Kosovë \\ \{muhamet.ahmeti, mimoza.sylejani\}@ubt-uni.net
}

\begin{abstract}
This paper presents the negative impacts on residential buildings in Kosovo, as well as the main factors of the occurrence of sick building syndrome (SBS) in residential buildings in the case of Kosovo. It also examines the impact of different materials on this phenomenon and how many constructions in Kosovo are protected from this phenomenon.

For the assessment of the impact of materials on the health and the environment, it is necessary to consider all the phases. Starting from the construction phase, selection of materials, application from the beginning of the use of the building, including all the materials processing from the beginning until their application, the use of natural resources for the production of various construction products, the necessary energy for the production and processing of the materials used, and the amount of release and imitation of $\mathrm{CO} 2$ (carbon dioxide). This paper also discusses the question of what sick building syndrome SBS is, how materials are affected by this phenomenon, what are the main materials affecting the residential buildings in SBS phenomenon in Kosovo, what buildings are affected by this phenomenon and how does this phenomenon affect human health.

Furthermore, this paper provides a deep analysis on factors influencing the phenomenon of SBS in different municipalities and several companies. It also discusses the influence of Asbestos and its impact on SBS, through a survey conducted in different municipalities and institutions and other companies. Through this discussion the paper attempts to provide information on the current knowledge about asbestos, as well as the manner of its assembling and dismantling, storage and all other information related to this material which has a great impact on the appearance on phenomena of SBS.

A special emphasis has been put on the impact of materials on our health, recent research on the materials used and impact on the appearance of SBS case, including the diseases that occur as a consequence of the occurrence of diseased buildings.
\end{abstract}

Keywords: Kosovo, housing, phenomenon, life expectancy, SBS, Asbestos.

\section{Introduction}

People in the developed countries spend around $90 \%$ of their time indoors and around $20 \%$ in working environments ;During that time we are exposed to numerous health hazards that can be classified into biological, chemical, physical, biomechanical and psychosocial Exposure to these hazards could affect human health; Design of healthy and comfortable built environment is fundamental for the prevention and control of health hazards; The complaints may be localized in a particular room or zone, or may be widespread throughout the building; 600 office workers in the USA concluded that $20 \%$ of the employees experience SBS symptoms and most of them were convinced that this reduces their working efficiency. Study on 1390 
workers in 5 public buildings in Quebec, Canada showed that $50 \%$ of workers experienced SBS symptoms. SBS may also occur in other environments such as schools, kindergartens and residential buildings. In studies on residential buildings from $12 \%$ to $30.8 \%$ of occupants were identified as having SBS. The purpose of this study is to identify the main risk factors (asbestos and air pollution's) for SBS in Kosovo. Knowing these indicators that affects SBS buildings will help people increase their awareness.

\section{The term SBS "Sick building syndrome"}

The term "sick building syndrome", was first coined in the 1970s, It's recognition at this time may in part be attributable to the increasing presence of electronic equipment and other factors. It is used when the symptoms of a significant number of people occupying a particular building, are associated with their presence in that building. In most cases sick building syndrome occurs in office buildings, although it may also occur in other communal buildings such as schools and apartment buildings. According to the US Environmental Protection Agency (EPA), sick building syndrome is strongly suspected when the following circumstances are present:

- Symptoms are temporally related to time spent in a particular building or part of a building;

- $\quad$ Symptoms resolve when the individual is not in the building;

- $\quad$ Symptoms recur seasonally (heating, cooling);

- Co-workers, peers have noted similar complaints.

\section{SYMPTOMS OF SICK BUILDING SYNDROME}

- The common symptoms of SBS are listed here together:

- Headache;

- Eye, nose, and throat irritation;

- Dry cough ;

- Dry, itchy skin, rashes ;

- Dizziness and nausea ;

- Difficulty in concentrating ;

- Fatigue ;

- Sensitivity to odours.

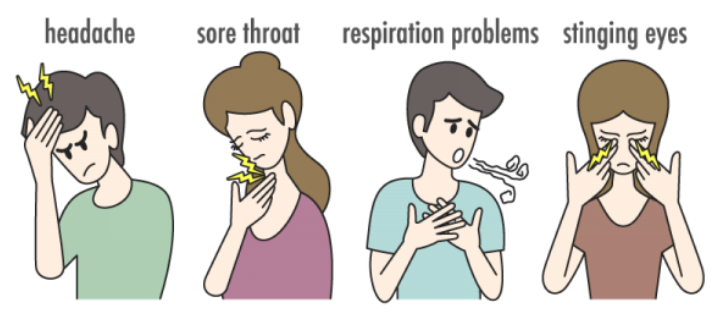

Photo. 11. https://www.scoop.it/t/genocon-2?page=3 


\section{SBS symptoms in offices}

In 1984, a WHO Committee Study reported $30 \%$ of new and redesigned buildings worldwide complaint of the indoor air quality

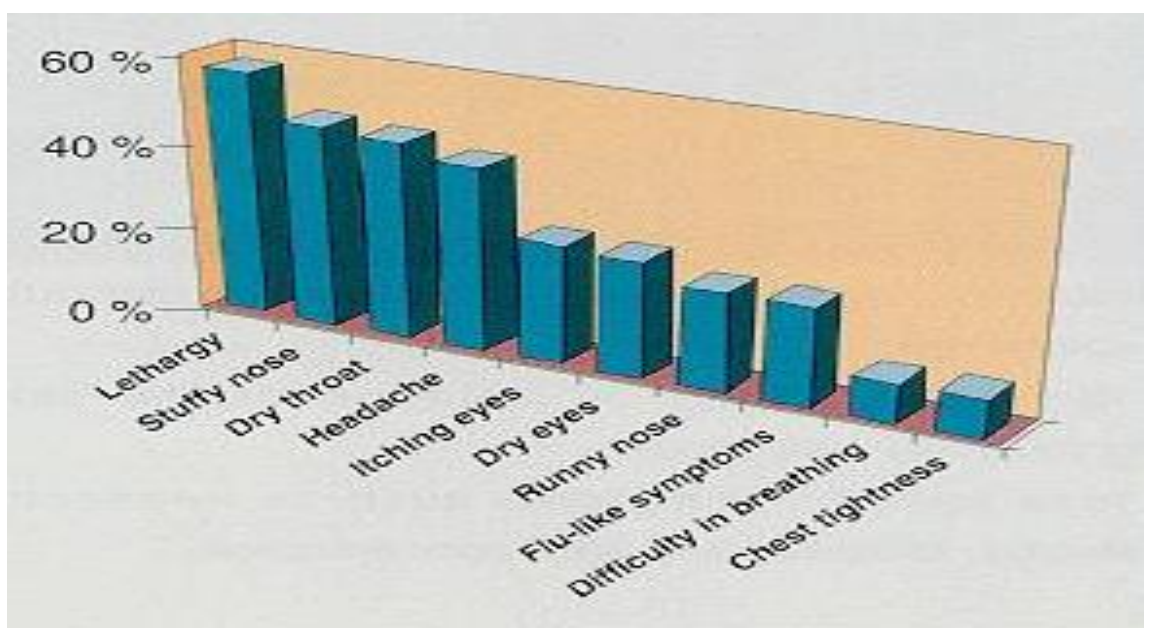

Photo. 2. https://www.scoop.it/t/genocon-2?page=3

\section{Sick Building Syndrome - what is it?}

Sick building syndrome (SBS) is a combination of ailments (a syndrome) associated with an individual's place of work (office building), school, or residence. The term "sick building syndrome"(SBS) is used to describe situations in which building occupants experience acute health effects that appear to be linked to time spent in a building, but no specific illness or cause can be identified.Most should improve within hours of leaving the problem buildings. The complaints may be localized in a particular room or zone, or may be widespread throughout the building.

\section{SBS - where does it happen?}

Mostlyhappensinside office environments. Similar problems could occur in schools, hospitals, homes etc. Indoor air problems in domestic welling's, esp. associated with water damage (Nordic countries' definition).

\section{Factors related to increased prevalence of SBS}


- Personal factors: Lower status in organization, menial job.

- Individual factors: Paper dust; cigarette smoke; office dust; more use of computers ;

- Building factors: High indoor temp.; low fresh air ventilation; poor individual control of temp. and lighting; air conditioning; poor maintenance; poor cleaning; water damage ;

- Building material factor: factors of building materials: asbestos, carcinogenic materials, synthetic materials, polymers;

- Environmental factors: air pollution, atmospheric conditions, environmental pollution.

Air quality report for the period of November to December 2016 and January 2017 in Kosovo

- Air quality is monitored through the automatic metering system that means it is done continuous measurements without interruption;

- The parameters that are monitored are: Sulfur dioxide (SO2), Ozone (O3), NO2 nitrogen dioxide and PM10 and PM2.5 air suspended particulates;

- The results collected by the automatic measurement of the pollutant parameters are processed, validated and analyzed to give an assessment of the condition of air quality in the monitoring area;

- The assessment of air quality is done by comparing the values of the results obtained with the standard values allowed under applicable laws and regulations in force and according to the 2008/50 EC Directives for Europe's Cleanest Airways.

- From the analysis of the results obtained by automatic air quality monitoring is ascertained during the monitoring period November - December 2016 and January 2017 are present exceedance of daily limit values with PM10

- Daily limit value allowed for human health protection is $50 \mathrm{ug} / \mathrm{m} 3$. As far as the days are over allows up to 35 days to exceed PM10;

- All of these months have been recorded 46 days (cases) exceeding the permissible values of PM10. In November, 10 days (cases), in December, 21 days (cases), and in January 15 days (cases).

- $\quad$ The maximum value was recorded $254.9 \mu \mathrm{g} / \mathrm{m} 3$, on 29.01.2017.

- In January of this year 2017 we had a total of 15 days with exceeding the PM10;

- In the following year, we recorded a total of over 53 days (cases) which means that we have 18 days behind allowed standards;

- But compared to 2015 we have an improvement of air quality, since in the above mentioned year we had 73 days with exceeding the PM10.

\section{Asbestos - presence in various construction positions in Kosovo}

- Asbestos is one of the deadliest materials linked to the hard to detect sick building syndrome (SBS) ;

- $\quad$ SBS can occur when people are exposed to air pollutants indoors in either a home or a business and can cause illness or even lead to diseases which can be fatal. Sick building syndrome can be caused by a wide variety of pollutants including but not limited to nitrogen dioxide, Sulphur dioxide, carbon monoxide and heavy metals such as mercury and lead ;

- One particularly dangerous substance found in many older homes ;

- While asbestos is sometimes linked as a cause of sick building syndrome, it is often referred to simply as a building related illness, rather than being grouped in the more general sick building syndrome ; 
- Asbestos is a serious threat to the health of any individual who comes into contact with it.

\section{Asbestos - its presence in Kosovo}

The presence of this material in Kosovo has increased. In Kosovo a factory for the production of concrete asbestos elements has been operating, producing various elements which are used in different construction sites. The factory was located in Kaçanik and now is closed, but the remains of this material are very large and are not protected or stored in a certain way for this material. Also this material has found a great use also as a combination of concrete asbestos, in the form of tiles or pipes of different dimensions, where even now in the Municipality of Pristina are mounted about $3.4 \mathrm{~km}$ water pipes that is in operation.Generally this material have a great use in Kosovo, it has been studied part of the Pristina municipality in a diameter of 500 $\mathrm{m}$, we have encountered about 7 houses where the concrete asbestos material has found a use.



Photo 3. Pristina city. 


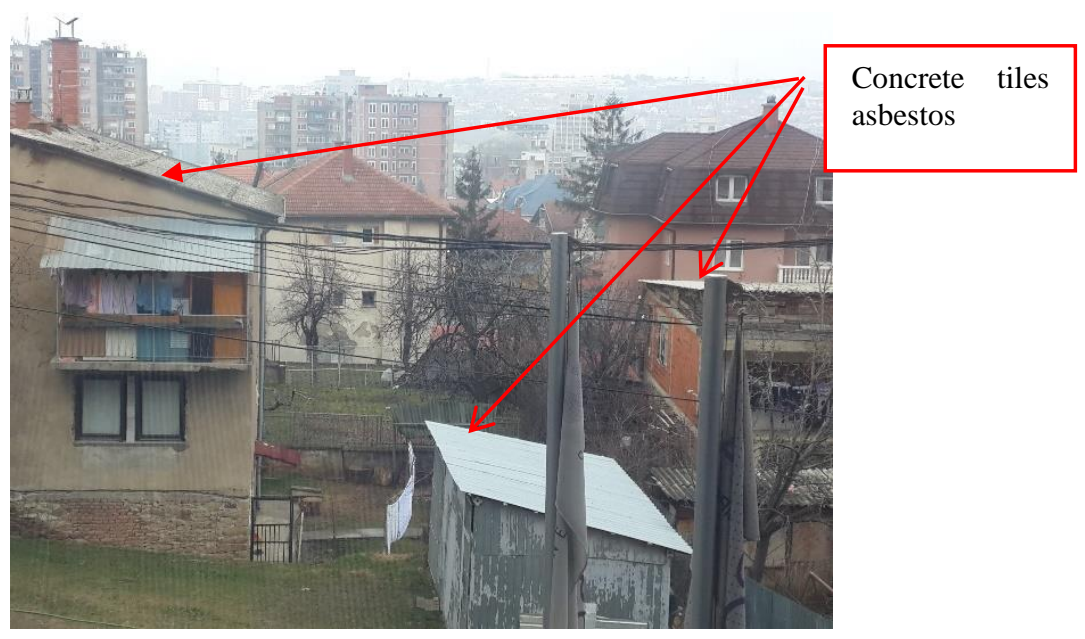

Photo 4. Pristina city

Having this fact, we have prepared a questionnaire where we have identified how much municipalities are informed to have this material as very problematic for the health and the environment we live in, knowing that represent the main factorwhich affects the phenomenon of sickly SBS buildings. A questionnaire was conducted in this paper where we have identified how many municipalities in Kosovo are familiar with this material - Asbestos.They identified buildingshavingthis material, how municipalities are handlingthis information, removal of deposition and all the procedures they need to remove this material from various buildings and warehousing and, its conservation. Also, how the municipalities where informed, connection between the relevant ministry and municipality about the identification, materials, marking, removing, storing and conserving dangerous materials for human health as well as the environment.

The requested question (1): How much is the municipality informed or has information about the types of materials harmful to human health and the environment:

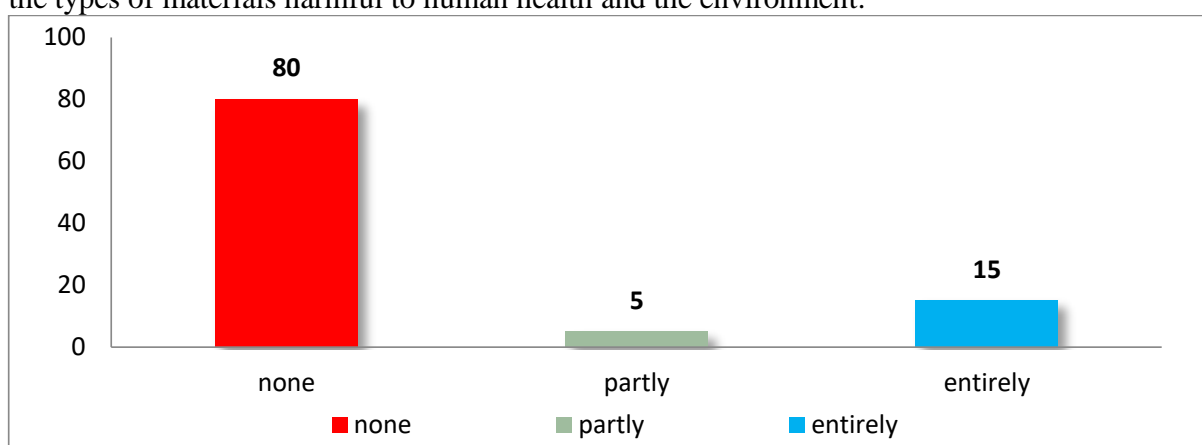

Fig. 1. The requested question (2): Has the municipality identified the harmful materials for health and the environment that are present in the territory of the municipality? 


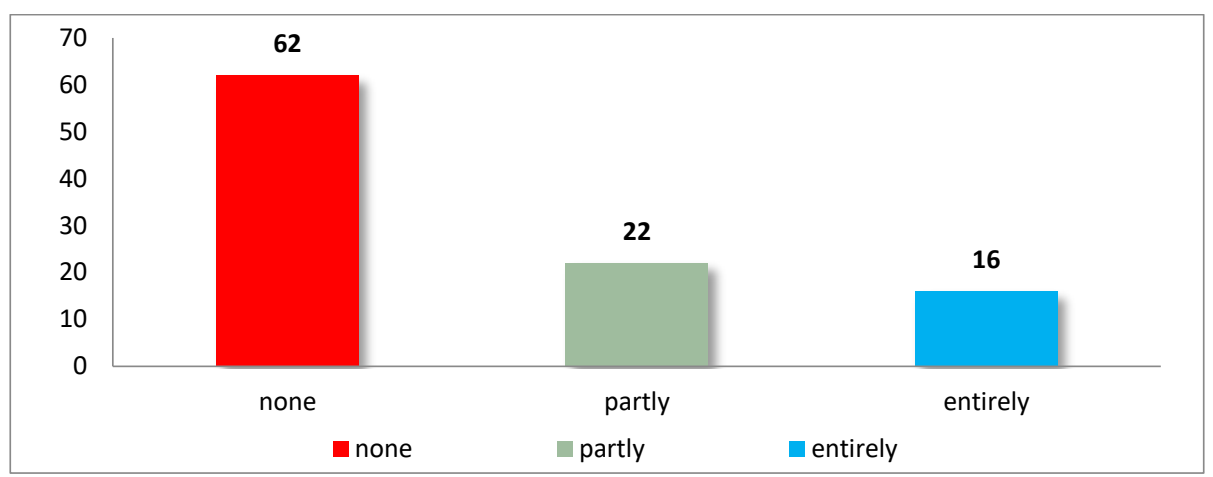

Fig. 2. Chart

The requested question (3): Municipalities (municipal directorates) have a list of materials that are present and pose a risk to people and surroundings in the respective municipality:

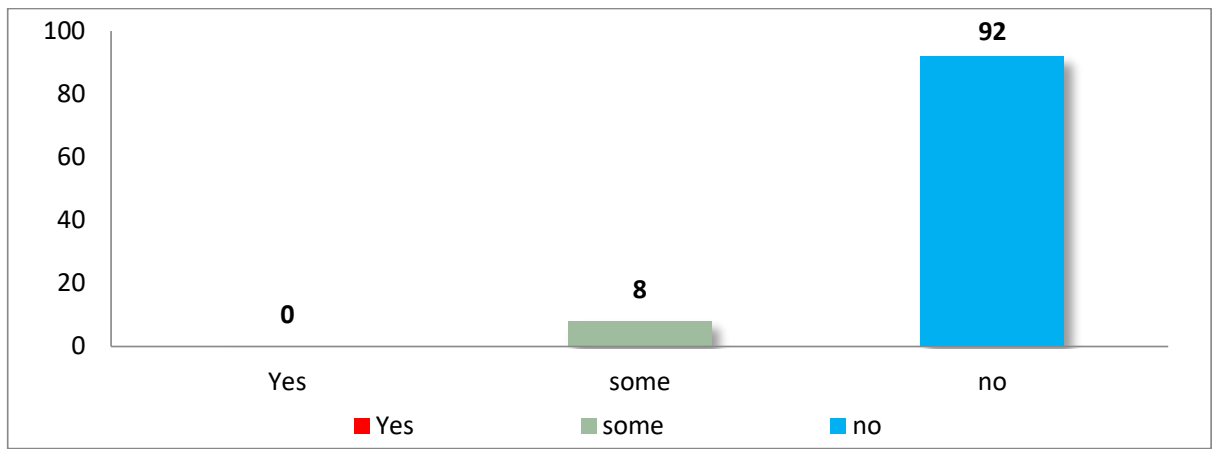

Fig. 3. Chart

The requested question (4): How much is the municipality informed about manner and procedures for removing or removing harmful materials for health and environment:

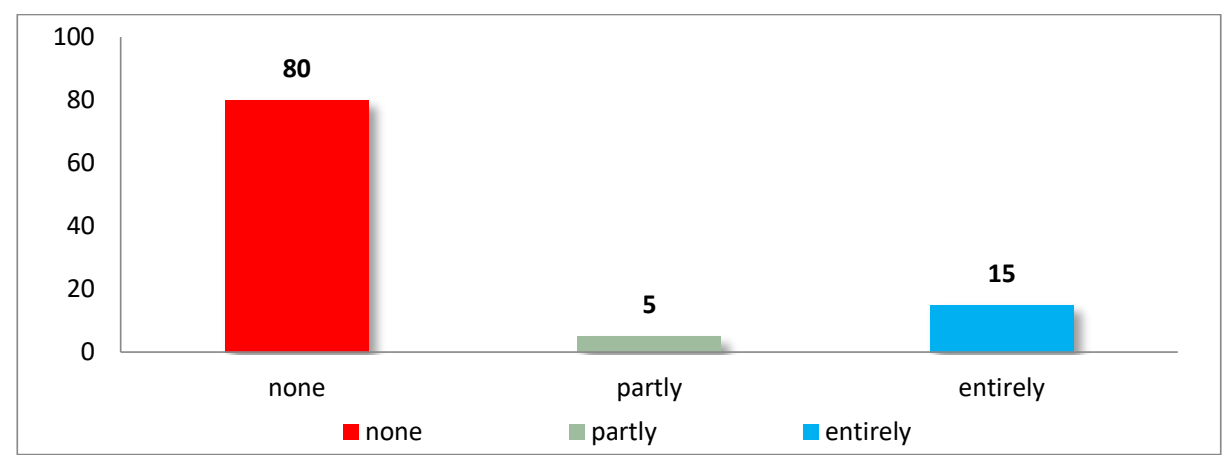

Fig. 4. Chart 
The requested question (5): Do the municipalities have specialized teams that eliminate harmful materials for human and environment health:

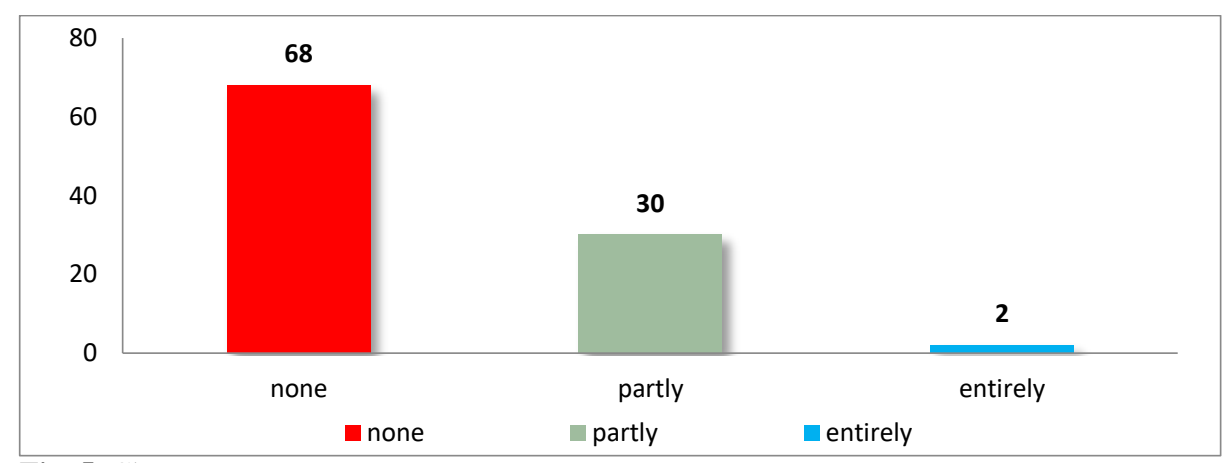

Fig. 5. Chart

The requested question (6): How much information's do you have about the materials that AZBEST has in its composition, such as asbestos materials such as concrete, tiles, pipes, ropes or other materials that contain asbestos or harmful materials as well as how much these materials (with composition of asbestos) are present in your municipality:

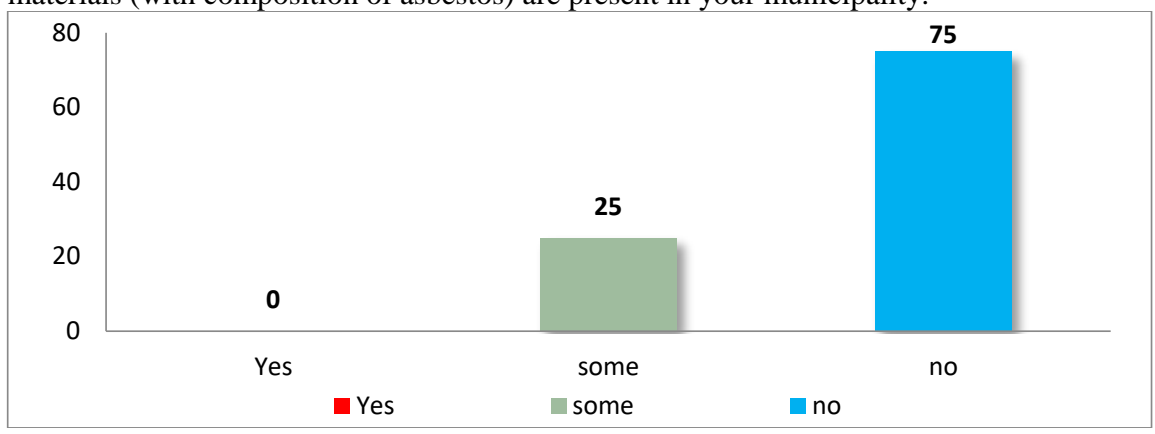

Fig. 6. Chart

The requested question (7): Has your municipality taken action in marking or identifying signs that in this area there are harmful materials for health and environment:

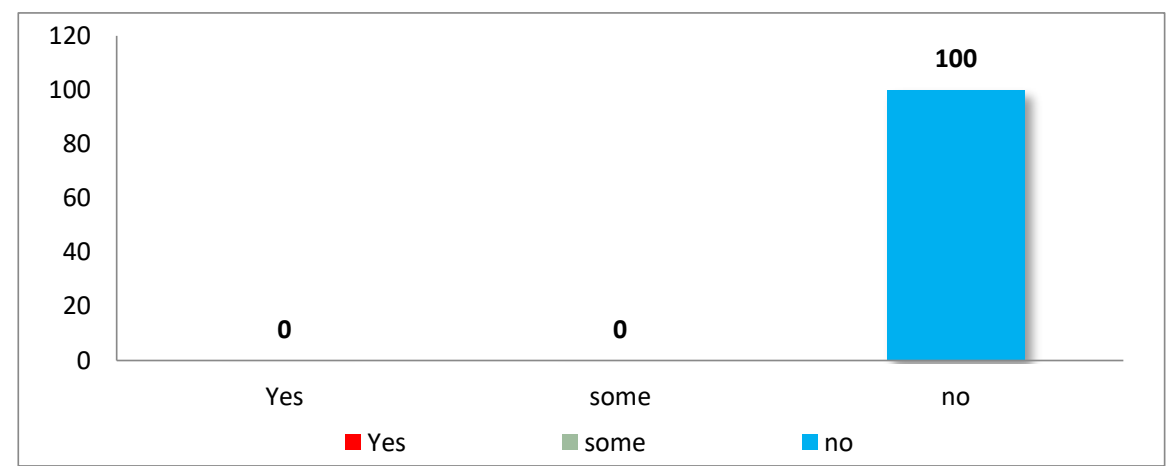

Fig. 7. Chart 
How do I investigate Sick Building Syndrome?

- A reasonable order of priorities for investigation would be:

- $\quad$ Look for the obvious ;

- $\quad$ Check the symptoms;

- $\quad$ Ask the staff what the problems are;

- If these fail,

- Check procedures and working practices;

- Seek professional help.

\section{Prevention measures to reduce potential for mold in new buildings}

- Territorial collaboration is important for the attainment of joined transport system. A more extensive worldwide neighborhood is essential.

- The developed formula for computing the economic impact of the transport on economic development in Western Balkan countries proved efficient

- The ability of governments to promote global logistics systems is limited by institutional \& organisational constraints and lack of knowledge of logistics developments and of the effects of their policy actions

- The factors: energy tax, environmental tax, and households consumption affect transportation

\section{Conclusions}

- Identification of risk factors for SBS and their relevant parameters presents an important step towards effective prevention and control of SBS symptoms.

- The current study especially the two main factors that are most dominant in Kosovo, air pollution and asbestos as a much-used material in different residential buildings and other facilities in Kosovo, covering the area, the $3,4 \mathrm{~km}$ water supply in the municipality of Pristina can lead to buildings that becomes chronically ill, and will pose a serious health and dyslexia problem and the work done.

- Therefore, suggests the use of an integrated safeguarding perspective, which implies that suspicious destructive factors should be removed as soon as possible from all project projects to be designed as well as additional measures, examining the possibility of eliminating these factors from swellings where this phenomenon is present.

- Developing a very powerful campaign where they will be informed, designers builders and all those responsible for the elimination of these factors that cause the phenomenon of SBS

\section{REFERENCES:}

1. Sick Building Syndrome Solutions in Australia, ecolibria - Building Biology

2. http://www.ecolibria.au.com/;

3. How to deal with SBS Sick Building Syndrome - Sanjay Chaudhuri ;

4. IAQ Publications - Sick Building Syndrome Fact Sheet http://www.epa.gov/iaq/pubs/sbs.html;

5. Boston Phoenix article on SBS complaints at Boston City Hall;

6. http://www.bostonphoenix.com/boston/news_features/top/features/documents/02229143.h tm;

7. Telegraph article about a study linking SBS to job stress; 
8. Inquiry into Sick Building Syndrome by NSW Parliament, Australia;

9. Chemical Injury Information Network http://ciin.org/;

10. US EPA Indoor Air Facts No. 4 (revised) Sick Building Syndrome

11. http://www.epa.gov/iaq/pubs/sbs.html;

12. Rutgers University Radon and Indoor Air Quality Tools for Schools Program and IAQ Video;

13. http://www.rutgers.edu/iaq. 